\title{
What matters in fostering adolescents?
}

\author{
Jo Lipscombe ${ }^{1}$ and Elaine Farmer ${ }^{2}$
}

\begin{abstract}
The White Paper Care Matters: Time for change (2007) sets out the British government's plans to improve outcomes for children in care. For example, a tiered model of placement types, structured around the level of complexity of children's needs, will inform placement commissioning. However, on the whole the White Paper does not differentiate between the needs of children according to age, even though evidence suggests that providing foster care for adolescents can be more challenging and complex than providing care for younger children. Drawing on a longitudinal study of adolescent foster care, this paper highlights some of the needs specific to adolescents, as opposed to younger children; the skills and strategies that carers need to develop to care for adolescents and the supports that children's services and other agencies should provide for such placements. The paper argues that increased attention to these issues would assist in sustaining the placements of the great majority of fostered young people who will not have access to highly specialised treatment foster care.
\end{abstract}

Keywords: fostering adolescents; foster care; foster carer parenting skills; support; strain; contact; education; supervision

1. Research Fellow, School for Policy Studies, University of Bristol

2. Professor of Child and Family Studies, School for Policy Studies, University of Bristol

Address for correspondence: School for Policy Studies, University of Bristol, 8 Priory Road Bristol BS8 1TZ. Jo.Lipscombe@bristol.ac.uk 


\section{Introduction}

Over recent years the proportion of adolescents looked after by foster carers has increased (Sinclair et al., 1995; Triseliotis et al, 1995; Packman and Hall, 1998; Department for Education and Skills (DfES), 2006) and it is known that the disruption rate for these placements is high (Triseliotis et al., 1995; Thoburn et al., 2000; Farmer et al, 2004; Sinclair et al, 2004a). The Green Paper Care Matters: Transforming the lives of children and young people in care (DfES, 2006) and the subsequent White Paper Care Matters: Time for change (DfES 2007) discuss the development of Multidimensional Treatment Foster Care (MTFC) for adolescents with extremely challenging behaviour and the wider extension of aspects of this programme. A tiered system of placement types for all other children, based upon the individual needs and requirements of the child, will be used to inform commissioning. However, neither paper attempted to delineate the specific task of fostering teenagers as opposed to younger children, even though the fostering of adolescents entails a range of issues and care-taking tasks specific to this age group that are less or not relevant to younger children. Whilst some adolescents will need the high level of support offered by MTFC and the Youth Justice Board (YJB) equivalent, Intensive Fostering, many adolescents will be well served by skilled foster carers with experience and knowledge of their needs. Given the challenges of caring for fostered adolescents (Walker et al., 2002; Farmer et al., 2004; Sinclair et al., 2004a), it is essential that appropriate training and support is provided for the carers of adolescents and the social workers supporting these placements, an issue that has gained recognition in the White Paper.

Adolescence is, in itself, a period of considerable ambiguity, which typically involves delicate negotiations between young people and their parents (Jones and Wallace, 1992). For looked after adolescents, this time can be even more challenging. For example, while young people living with their birth families are generally planning future occupations and qualifications, the priorities for adolescents in the care system may be in dealing with their relationships with family members or preparing to cope with early independence (Ward, 1995; Farmer and Moyers, forthcoming). Young people in care have to make a secure base in the foster family at the same time as they are striving to establish their autonomy. Similarly, they need to form their own identity while separated from their birth families (Aldgate et al., 1989). However, as a result of previous experiences and the number of adversities in their background histories, some adolescents in the care system are not yet ready for these developmental tasks. Conflicting loyalties and ambivalent feelings towards members of their birth families may further complicate this stage for some looked after teenagers. Downes (1992) concluded that foster families should provide fostered adolescents with a secure base from which they can reappraise and re-negotiate significant relationships, gain confidence in the wider world, and develop the capacity for mature independence. 
Although there are plans in the White Paper for looked after children to remain in care until they are 21 (and a presumption that they will remain at least until they are 18), the average age of leaving home for non-looked-after children is 24 (A National Voice, 2005). Further, the foster care system depends upon turnover to function, with children being 'exported' either to home or independent living (Sinclair, 2005). Given the current shortage of foster placements and the difficulties in recruiting sufficient carers, it will be a real challenge for local authorities to balance the tensions between providing foster placements for new care entrants and allowing existing looked after children to remain in their placements for longer. Thus, while the situation for care leavers is improving, they are still expected to be independent at an earlier age than their non-looked after peers, and there is a heightened need for them to attain tangible life skills whilst in placement to enable them to deal confidently with the transition to adulthood.

It is possible that policy and practice initiatives on fostering adolescents will become either overshadowed by developments such as MTFC and Intensive Fostering, or subsumed within general fostering for all children. We would therefore argue that care needs to be taken to ensure that the skills necessary for working with adolescents are recognised. The research on which this paper is based identified a series of particular parenting skills and supports that contributed to successful outcomes for fostered adolescents, which will be discussed below, once the research study has been outlined.

\section{The research}

The research was funded by the Department of Health (Farmer et al., 2004) and was conducted in England. The primary aim was to discover how far foster carers' parenting strategies and the supports they receive relate to the outcomes of placements for adolescents, and which other characteristics within the child or the foster family relate to the stability and effectiveness of placements.

The study used a one year prospective, repeated measures design and was based on a consecutive sample of 68 newly placed young people aged 11 to 17, whose reasons for admission included concerns about their current behaviour and/or emotional well-being. The young people were drawn from specialist and mainstream fostering schemes in 14 local authorities and two independent fostering agencies. Certain types of placement and categories of young people were excluded as the caring skills necessary in these situations, or the supports provided, were considered likely to be markedly different from the target population. Therefore young people in respite placements, mother and baby placements, those remanded to foster care, young people with severe learning difficulties. and asylum seekers were not included. Placements with family or friends were also not included as these formed the basis 
for a separate study of kinship care (Farmer and Moyers, forthcoming).

Data were collected in three ways: through a review of the young people's case files; through semi-structured interviews with the young people, their foster carers and social workers; and by standardised measures. Interviews were conducted at three months and 12 months after the start of the placement, or at the point of ending if this occurred earlier. Two outcome measures were chosen to provide a broad overview of the placement:

1. a simple rating of placement disruption or continuation ( $40 \%$ of the placements had disrupted by the 12 month follow-up);

2. a rating of the quality (or 'success') of the placement for the young people, in terms of how beneficial the placement had been for them.

Forty seven per cent of the placements were rated as 'successful' because they were continuing well or had had planned positive endings by the one year follow-up.

\section{The foster carers}

Just under a third of the foster carers were single (31\%), while the remainder had a partner. The ages of the carers ranged from 28 to 67 years, with just over half (53\%) aged between 41 and 50 years old. Ninety three per cent of the carers were white and of British origin; one was from a European background, two were African-Caribbean and two were of mixed ethnicity. Four per cent of the carers had been fostering for less than a year and 33\% for between one and five years. Nearly a quarter (24\%) had been fostering for between five and 10 years, $21 \%$ for $10-15$ years and a further $18 \%$ for 15 years or more. Moreover, $62 \%$ of the carers were part of a specialist fostering scheme.

\section{The young people}

Of the 68 young people interviewed, 35 (51\%) were girls and 33 (49\%) were boys. Their ages ranged from 11 to 17, with a mean age of 14.25 years. Eighteen per cent of the young people were from black or minority ethnic backgrounds, including nine young people who were of mixed ethnicity, two who were African-Caribbean and one who was Asian. Eighty three per cent of the young people were placed with foster carers of the same ethnic origin. As would be expected, analysis of the young people's case files indicated that the majority of the young people had experienced marked adversities during their childhood, including family disruption, physical and sexual abuse and neglect.

Not surprisingly, given the extent of these adversities, the young people in the 
sample often had complex care histories; only 39\% of the young people had no previous experience of care, although some of these had been looked after by family or friends. The young people also demonstrated many behavioural and emotional difficulties. For example, over two thirds showed challenging behaviour at home (76\%) or outside the home (68\%), and over half (56\%) displayed violent or aggressive behaviour. Forty per cent had either been cautioned or had a criminal conviction, and 32\% had abused drugs or alcohol. Almost a fifth (18\%) were involved in risky sexual relationships and 16\% showed inappropriate sexual behaviour, with a further seven per cent showing sexually abusing behaviour. Just over a fifth (22\%) had self-harmed and 12\% had attempted suicide. Furthermore, many of the young people had a disrupted educational history.

\section{Parenting fostered adolescents}

As outlined above, the previous experiences of looked after adolescents and the number of adversities they have suffered, combined with their age, mean that there are a number of specific care-taking or 'parenting' issues that need to be addressed within placements that are less relevant or which play out differently with younger fostered children. These issues include being able to respond sensitively to the young people, including responding to the young person's emotional age as well as their chronological age, facilitating their education and peer relationships, promoting their sexual health and relationships, and balancing the young person's need for safety with that for autonomy, in preparation for independent living. Carers also need to work with social workers to manage the young person's contact with their birth family, as will be discussed in detail later.

\section{Sensitive responding}

\section{Talking about the past and about family relationships}

Many young people in care may need to talk about their past histories and birth family relationships with an adult whom they trust. We found that placements were less likely to disrupt when the foster carers had been receptive to the young person's desire to share such sensitive information, and had made time for them to discuss difficult issues. Such sharing might bring greater closeness between the carer and the young person, enable confidences to be shared and help the young person to integrate past painful events. 


\section{Responding to the child's emotional age}

One particular aspect of sensitive responding that, in itself, was related to the success of adolescent foster placements was the carer's ability to respond to the child's emotional age. Many adolescents in foster care show evidence of behaviour more suited to younger children, while others appear to be functioning at a more mature level (Farmer and Pollock, 1998; Farmer et al., 2004; Lipscombe, 2006). This may of course also be a problem for younger children, but the discrepancy between chronological age and emotional age is likely to be more apparent and more extreme for older children. There were fewer disruptions when foster carers had been able to respond to the child's emotional age as well as their chronological age. For example, one 15 year old whose mother had died when he was 9 desperately missed physical attention. Although the carer said she felt uncomfortable with it, she allowed him to have a cuddle and suck his thumb for a while, as a younger child would, before encouraging him to act in a more age-appropriate manner. Such responsiveness indicates sensitivity to the need of many of these young people to rework some of their earlier missed developmental experiences, for example for children's play activities and nurture, and a willingness to supply some of these in the placement. It implies tolerance and understanding that looked after adolescents who may appear superficially street-wise and 'mature' may need a regular opportunity to regress in their behaviour, alongside the more general routine of age-appropriate activities and relationships. This has implications for the training needed by carers and suggests the need for a greater focus on child development and an increase in awareness of the potential disparity between a child's chronological age and their emotional or developmental age.

\section{Facilitation of education}

As with many children within the care system (Jackson, 1994; Borland et al., 1998; Harker et al., 2003; Social Exclusion Unit, 2003; Taylor, 2006), the majority of the young people in this study had experienced high levels of educational disruption and had low levels of educational attainment. A lack of educational skills makes careleavers particularly vulnerable to unemployment and is associated with involvement in offending behaviour and social exclusion (Farrington, 1996; Taylor, 2006). Section 52 of the Children Act 2004 places a statutory duty on local authorities to promote the educational attainment of looked after children, and the Green Paper (Department for Education and Skills, 2006) placed education at its centre. Both of these were written after this research was concluded. However, it appears that the implementation of both Section 52 and the proposals within the Green Paper may be difficult to achieve. For example, although the majority of the foster carers in the study were highly or fairly involved in facilitating the young person's education, 
encouraging the young person to attend school and showing interest in their achievements, $14 \%$ were not. We found that single carers were less involved than others in young people's education, probably because of time pressures associated with their higher levels of workforce participation, combined with lower levels of training and support. In addition, Jackson (2007) suggests that carers who are not involved in young people's schooling might not accept the promotion of education as being part of their role and, furthermore, that social workers might be reluctant to place pressure on the carers to support the child's education for fear of losing the placements. For this reason, the plans in the White Paper to emphasize educational support in training for foster carers and in the National Minimum Standards for fostering services are very welcome.

Placements in our study were more likely to break down if the young person had low confidence in their school work. As Taylor (2006) argues, looked after children too frequently have to move schools when they move placements (see also Sinclair, 2005); these children may find that their coursework is disrupted (which is particularly problematic for those studying for GCSEs) - an issue which has been taken up in the White Paper - and they may lose confidence in their achievements. It is likely that providing additional support, encouragement and assistance to these teenagers could increase their confidence levels and enhance placement stability as well as helping to maximise their educational progress and employment opportunities (see also Jackson and Ajayi, 2007). Taylor (2006) also found that developing new skills, making new friendships and joining new groups at school could help prevent young people from truanting, social exclusion and involvement in offending behaviour. The range of proposals in the White Paper to support the education of looked after children, including a much greater emphasis in social work training on the importance of education and social relationships, is therefore very welcome. Social workers need to be actively involved in organising educational support for young people and ensuring that foster carers are also highly involved, and that their mutual roles are clear. Both also require education departments to provide suitable school placements and referrals for more specialist help in a much more timely way than has been the case in the past. It will be interesting to see how far new joint structures for children's services and education facilitate this.

\section{Facilitation of friendships and activities}

Establishing and maintaining good peer relationships is an important aspect of adolescent emotional and behavioural development, yet many young people in care have problematic peer relationships (Hodges and Tizard, 1989; Quinton et al., 1998). The development of positive relationships and activities is important for the promotion of self-esteem and confidence, can help to expand the opportunities available to young people and promote resilience (eg Gilligan, 2000, 2001). 
Furthermore participating in hobbies and activities can contribute to educational progress for children in care, by encouraging engagement with prosocial adults and by the implicit learning opportunities (Gilligan, 2007).

Interestingly, young people who, at the outset of the placement, had difficulties in making and maintaining adequate peer relationships had significantly fewer disruptions and more successful placements than those who had positive peer relationships. These teenagers had either no friends or, whilst good at making initial contact with other children, could not sustain the relationship. Some sought the company of younger or much older children, or established exclusive relationships with the opposite sex, which excluded them from 'normal' peer relationships. The foster carers needed to provide these young people with one to one nurturing to help them overcome their previous dysfunctional relationships and to develop a positive relationship with caring adults, before assisting them to develop their peer relationships.

The research findings further showed that young people who had some special skills or interests of their own were significantly more likely to have good quality placements than those who did not. Young people who spend their time in positive activities also have less time to become involved in anti-social behaviour. In addition, carers who are involved and interested in young people's free time are likely to have more awareness of their activities outside the home and thus have more ability to supervise them outside the placement. Many of the young people did not see themselves as requiring assistance with activities which may have deterred the carers from helping. However, over half of the carers were involved in arranging or suggesting activities for the young people. Carers need to be encouraged and supported to view the fostering task holistically and to consider the management of the young people's friendships and activities outside the placement as an integral element of their role.

\section{Promoting sexual health and relationships}

As adolescence is typically a time of increasing sexual awareness and sexual activity, carers have an important part to play in promoting fostered adolescents' sexual health and relationships (Knight et al., 2006). However, this proved to be a more problematic area of parenting and a significant proportion (20\%) of the carers had little or no knowledge of the young person's relationships. Over half of the foster carers were concerned about the young people's sexual relationships, but few actually talked to them about their concerns. Two fifths of the carers did not discuss sexual health and sexuality with the young person, and they were less at ease discussing sexual matters with boys than girls. Many looked after young people are poorly informed about normal sexual development, sexual health or contraception (see, for example, Farmer and Pollock, 1998) and need the opportunity to talk about these issues and 
their relationships. There was considerable confusion over whose responsibility it was to talk to the young people about sex and sexual health. Some carers believed (or had been told) that the social worker would assume this responsibility, yet this was not happening. The high levels of young people leaving care who are either pregnant or who already have children (Corylon and McGuire, 1997; Haydon,, 2003) is testament to the fact that these young people may need greater advice or support in managing their sexual relationships. The need for sexual health and relationship advice to be included in residential and foster carer training is recognised in the White Paper. However, it is equally important that foster carers (or others nominated to help) feel empowered and supported to take on this responsibility. In addition, young people with backgrounds of sexual abuse may need more specialist help to address these issues (Farmer and Pollock, 1998).

\section{Developing independence}

Parents and carers of adolescents have to maintain a balance between ensuring young people's personal safety and enhancing the development of their autonomy, particularly as they start to prepare for independent living (Walker et al., 2002). Suitable boundaries for the young people need to be established so that their behaviour can be contained, without being too restrictive or permissive, taking into account their developmental and emotional age. Judging where to set the boundaries for looked after adolescents is sometimes very difficult. The study suggests that in some ways it is the reverse of normal child development where boundaries are established early and gradually relaxed as the child grows. Many of these teenagers had not had consistent boundaries set before and some were unaccustomed to any restrictions on their behaviour. We found that in the latter situations foster carers made most progress if they set a few loose boundaries to begin with and then gradually established more boundaries to bring the young person into a more normative range - at the same time as encouraging the young person to become independent.

Integral to establishing appropriate boundaries is the supervision of the young person, the awareness of where the adolescent is, who they are with and what they are doing. Adolescents, partly as a result of their stage of development, may be more likely than younger children, to succumb to environmental pressures to engage in activities of which adults disapprove. Good supervision outside the home was linked to improved placement outcomes and is important in keeping young people safe in terms of involvement in offending, prostitution, drug and alcohol misuse, and sexually high risk behaviour. Carers were more likely to increase their supervision within the home if they were concerned about the young person's use of drugs or alcohol, but not outside the home. This suggests that the carers' increased concern may be related to the protection of their own children or other fostered children, or 
it may be that the carers do not see their role as extending to supervision outside the placement. Carers can more easily have an influence within the home and the young people are likely to be more amenable to control within this placement setting than outside it. However, these young people are often at risk outside and it may be that there are opportunities for carers to extend their monitoring role, for example by offering lifts, talking to the young people about their friends and intervening if children make contact with high risk individuals (see also Farmer and Pollock, 1998; Stace and Lowe, 2007; Lowe et al, 2007).

All young people need to develop self-care and life skills to enable a successful transition to independent living. However, for many looked after adolescents, a return home will not be envisaged and they may have to become self-sufficient and independent at an earlier age than other teenagers (Walker et al., 2002; Sinclair et al., 2004b; Sinclair, 2005). Despite the plans in the White Paper that children will be entitled to remain in care until they are 21 , some may decide to live on their own before then (Taylor, 2006) and need to be supported to do so. Young people who have not been looked after have the option of returning home should independent living become problematic; this not always possible for looked after children. Carers need to find a balance between encouraging the development of life skills and self-efficacy whilst enabling the young person to feel settled and secure in the foster family. In our study, carers who involved the young people in an average level of preparation for leaving care were significantly more likely to provide good quality placements for the young person overall compared with those who involved the young people in either little or high levels of preparation. Not helping the young person develop life skills would put them at a disadvantage when they left care but perhaps too much of an emphasis on independence meant that the young person did not settle as well within the placement or that the placements was never seen as more than a short-term bridge to independence.

\section{Supporting adolescent foster placements}

Social workers and others supporting adolescent foster placements need to be aware that the quality of parenting provided by the carers can be adversely affected in certain circumstances. For example, foster carers' ability to parent the fostered young people decreased when the carers were experiencing significant stress or when the fostered adolescents had a negative impact on other children within the household (Lipscombe et al., 2003, 2004). Social workers need not only to be aware of the stresses and strains carers often experience when caring for teenagers, but also to provide effective and timely support, including arranging the provision of 
appropriate therapeutic help for young people when it is needed. Furthermore, planning and preparation for the placements is critical for both the foster carers and the young people to ensure that the placement begins in a positive manner, that a package of support is in place and, in addition, partnership working is needed with the foster carers to pro-actively manage the young people's contact with birth family members.

\section{Preparation for placement}

The practice and research literature lays considerable emphasis on the importance of preparation of children for placement and of giving adequate information to carers (Farmer and Pollock, 1998; Quinton et al., 1998; Triseliotis et al., 2000; Sinclair, 2005). Our research suggests that adequate preparation can make a real difference to outcomes for adolescents: placements in which the young person felt that they had been given adequate information about the carers and their family before the move were more likely to be rated as successful and were less likely to break down. However, a third of the young people said that they had not been consulted about the move, and a third had not had an opportunity to meet their carers before moving to the placement. Furthermore, two-fifths of the carers said that there was information about the young person that they had needed and did not have and almost a quarter had been given information that was neither accurate nor up to date. There was a tendency for social workers to give less information about the children with the more disturbed behaviour, yet there were significantly fewer disruptions when the young people had been no more difficult to manage than the carers had expected. This suggests that, within certain parameters, foster carers may be able to manage difficult adolescents as long as they take them with full knowledge of their difficulties. It is clearly also critical to provide full information to the carers to prevent high risk adolescents from being placed in situations where they pose risks to other children in the family, for example as a result of sexually abusing or aggressive and violent behaviour.

\section{Foster carer strain}

Where foster carers had experienced a high number of stressful events (such as bereavements, relationship difficulties, illness or financial worries) prior to the placement there was an increased risk of disruption (Farmer et al., 2005). Strain was also particularly evident during the placements when the carers had only accepted the placed young person with reluctance, or under some pressure, or if the adolescent had considerable behaviour problems, including conduct disorder and hyperactivity. The link between an accumulation of stress and higher levels of 
placement breakdown may in part relate to the lower levels of positive parenting shown by these carers and their reduced capacity to ensure that the young people's needs were met (for example for appropriate education or counselling). Carers under strain responded less sensitively to the young people, were less able to respond to their emotional age, and gave little attention to preparing them for independence. Strained carers also felt less supported than others; these carers significantly more often than others found the children's social workers difficult to contact and more often felt that their views were not taken seriously by the professionals involved with the young person. Family placement workers must therefore assess the level of strain carers are under before a placement is even made, and also be alert for signs that carers are under strain during the placement so that they can intervene before the capacity to care for the young person deteriorates.

\section{Contact with birth family members}

The ability to parent the fostered young person could also be undermined by the influence of the birth family. Whilst contact for all looked after children is a complex phenomenon (see, for example, Sinclair et al., 2004a; Moyers et al., 2006), there is a widespread idea that, because of their age, adolescents can manage the practicalities of contact for themselves and that foster carers and social workers need to be less involved in arrangements (Sinclair, 2005).

In this research, however, contact for the majority of adolescents was often very problematic and was one of a number of factors that led to placement breakdown. At the start of the placement a third of the foster carers felt that the contact arrangements were not in the best interests of the young people, and almost half considered that the young person placed with them had difficulties in their contact with family members (Moyers et al., 2006). Typical difficulties were continued rejection, unreliability, neglect and abuse by parents during contact. Furthermore, birth family contact could undermine the influence of the foster carers, particularly if family members encouraged anti-social or risk-taking behaviour. At the one year follow-up, almost two thirds of the young people had contact with someone who was rated by the researchers as detrimental to them, and a third had no beneficial contact with anyone.

Legal arrangements did not always protect young people who were determined to keep in contact with family member. Even if it was prohibited or if the foster carer or social worker thought it was not in the child's best interests, some of the children themselves chose to maintain contact. For example, one 15 year old boy made many visits to his mother at her home, even though his violent step-father was there and subjected him to numerous physical assaults. These adolescents may need additional work to help them understand their family relationships, to negotiate appropriate contact, and to keep themselves safe if they are determined to keep in touch. 
The difficulties encountered by young people whose contact was not supervised were not always apparent to their social workers. Many of the foster carers were in a good position to observe the effects of contact on the young people they looked after, and regular discussion between the social worker and foster carers would assist in keeping matters under review. In those cases where social workers took action, changes usually resulted in definite improvements for the young people and their placements. The changes were often quite small adjustments to the frequency and duration of meetings, or the involvement of other more positive relatives (see also Marsh and Peel, 1999). While there may be limits on how far long-standing relationship patterns between children and their birth parents can be changed, the negotiation of meaningful contact is an important task and more work with young people is needed to assist them to understand and manage their relationships with family members more effectively. When negative relationship patterns persist, young people need help in integrating the reality of their parents' actions and in dealing with their own experiences of rejection and loss in ways that allow them to move on, build up a sense of self-worth in spite of these experiences and make use of other more sustaining relationships. Their ability to form and maintain healthy adult relationships is likely to be seriously jeopardised if they are not given assistance in dealing with these issues.

\section{Placement support and services}

It was clear that, for the foster carers, appropriate help for the young people was a crucial strand in their overall support systems. Over a third of the young people were seeing a specialist for counselling and carers tended to feel better supported when this was the case. Conversely, when foster carers considered that a young person needed specialist help and it was not provided, this did much to make them feel unsupported. Over and above this, there were fewer disruptions when appropriate therapeutic help was provided for young people (or was not needed) and more successful placements when young people reported that they were receiving such assistance. There were more disruptions when carers had felt the need to seek mental health help for the young person but had been unable to locate such assistance.

Foster carers who were looking after teenagers with either conduct problems or hyperactivity had great difficulty in coping with these young people on their own without support services (see also Quinton et al., 1998). A significant proportion of these carers had asked for help, primarily for the young people but also for themselves, but most had received either no assistance at all or a service that was inadequate or insufficiently tailored to the needs of the young people and their carers. Clearly, young people who have severe behaviour problems or are hyperactive require intensive packages of support if their placements are to survive.

Carers who had a lot of support from their own children (including adult 
children) had fewer placement disruptions, as did those who received substantial support from other family members (principally their parents and/or partners). In addition, there were significantly more successful placements when the carers were supported by their social networks and local professionals, such as doctors and teachers. Placements were more often successful when the social workers had arranged some services for the young people, and importantly support from the young people's social workers themselves was significantly related to the success of the placement. The intention in the White Paper to use weekly foster carer meetings and the Parent Reports on young people's behaviour (from the MTFC) in order to identify and focus services on the placements most vulnerable to disruption could prove useful, particularly as we found that foster carers under the most strain received the fewest social work visits.

\section{Implications for policy and practice}

The placement outcomes in this study show that adolescents with considerable emotional and behavioural difficulties can be successfully placed in mainstream and specialist foster care placements and not all will need the high levels of support provided in MTFC placements. Indeed, it is of note that the behavioural, emotional and educational difficulties experienced by these young people reflect those experienced by the young people placed in MTFC (Roberts, 2006), and the overall success rate of these placements is not dissimilar. A third (31\%) of the children placed in MTFC were classified as 'early leavers', with their placements having disrupted, compared with $40 \%$ of those in our study.

Foster carers within mainstream and specialist schemes can provide high levels of positive parenting for adolescents if sufficient training and support is provided, and if the parameters of the foster carer's role are clearly and unambiguously delineated. In particular, placement outcomes for adolescents are likely to be improved if foster carers are trained to: respond to the young people's emotional and developmental age; talk to young people about the past and about difficulties in their relationships with their families; monitor adolescents' activities outside the home (see also Stace and Lowe, 2007); and assist young people to develop independence and autonomy whilst also providing them with a secure base. Furthermore, foster carers need to be encouraged to view their role as extending beyond the boundaries of the home to facilitate the young people's education, activities and peer relationships.

Whilst Jackson (2007) argues that some foster carers do not see their role as encompassing the facilitation of education, the consultation responses to the Green Paper suggest that more responsibility for promoting children's education could be invested in the carers themselves. However, to enable carers to take on this role they will need further training to help them to understand the educational system and 
in supporting learning at home (including through leisure activities and hobbies), as recommended in the White Paper. In addition, an examination of any specific barriers to single carers being fully involved in education would be useful. Regular contact between the school and the carer is critical and schools need to reciprocate the carer's commitment to young people. Social workers and foster carers need to be clear about their respective responsibilities with regard to schooling, for example who should arrange meetings with the school or attend parents' evenings (Sinclair, 2005). It is also important that education departments become much more active in providing suitable educational placements for children who are looked after and in sustaining the education of children at risk of school exclusion. For placements where there is no educational provision at all, an education worker could be assigned to help the carer access education on the behalf of the young person (see also Walker et al., 2002), a model that is routine and works well in some independent fostering agencies. The range of policy changes in the White Paper which address education could make a real difference to the capacity of placements to contain young people as well as to their educational experiences while in care.

Clarity is needed as to who has responsibility for some areas of parenting that have particular relevance to adolescents, for example whether foster carers or social workers have responsibility to promote the young person's sexual health and safe and positive sexual relationships. Whilst the White Paper addresses the training needs of foster carers in this area and some professionals suggest that the young person should be able to talk to the person with whom they feel most comfortable (Knight et al., 2006), we would argue that there needs to be a nominated person (arguably foster carers since the young person will have most contact with them) who ensures that the young person has had the opportunity to discuss sexual health, contraception and relationships, even if they choose to discuss these issues with someone else.

Social workers and foster carers also need to work together to help the young person negotiate and manage appropriate birth family contact. Adolescents are more able to take the initiative in arranging contact with their birth family than are younger children, yet this can expose them to unsatisfactory and sometimes harmful contact. Social workers in Cleaver's study (2000) had limited time for work relating to contact, and this is an area where foster carers could take on more responsibility, particularly as we found that they were often more aware of ongoing contact issues than the social worker. Cleaver (2000) found that carers who had formal training on contact were more likely to have established positive relationships with parents and to be involved in contact arrangements.

In the study, high quality support from social workers and other professionals was related to less strain for foster carers and to better parenting skills and so to better placement outcomes. Good social work support for placements is arguably one of the major contributions of independent fostering agencies (Farmer et al., 2007). For this to occur in local authorities as well, children's social workers in 
particular need the kinds of caseloads and team structures that would allow them to give due time to looked after young people and their carers. In addition, therapeutic help is important for some young people and helps to support their placements. Thus, improved support and services for foster carers and young people are crucial elements in improved services.

Whilst the White Paper has included policy changes in many of the areas mentioned, the details of many are awaited. It is not always clear how proposals will be resourced or how real leverage can be brought to bear in some key areas, for example, in providing better access to counselling and mental health services for looked after young people, or in improving the support and services available to foster carers. Nonetheless, it is to be hoped that local authorities will seize the initiative provided by the White Paper. Addressing the specific needs of fostered adolescents and their carers will help to sustain the placements of the majority of young people in care who will not have access to highly specialised treatment foster care.

\section{References}

Aldgate, J., Maluccio, A., and Reeves, C. (1989) Adolescents in foster families: An overview. in J. Aldgate, A. Maluccio, and C. Reeves (Eds.) Adolescents in Foster Families. London: Batsford

A National Voice (2005) No Place Like Home. Manchester: A National Voice

Barnardos (2006) Failed by the System. Ilford: Barnardos

Berridge, D. (1997) Foster Care: A research review. London: TSO

Borland, M., Pearson, C., Hill, M., Tisdall, K., and Bloomfield, I. (1998) Education and Care away from Home. Edinburgh: Scottish Council for Research in Education

Cleaver, H. (2000) Fostering Family Contact: A study of children, parents and foster carers. London: The Stationery Office

Corylon, J. and McGuire, C. (1997). Young Parents in Public Care: Pregnancy and parenthood among young people looked after by local authorities. London: National Children's Bureau

Department for Education and Skills (2006) Care Matters: Transforming the lives of children and young people in care. Green Paper Cm. 6932. London: TSO

Department for Education and Skills (2007) Care Matters: Time for change. Cm. 7137. London: TSO

Downes, C. (1992) Separation Revisited: Adolescents in foster family care. Aldershot: Ashgate

Farmer, E. and Moyers, S. (forthcoming). Kinship Care: Fostering effective family and friends placements. London, Jessica Kingsley

Farmer, E. and Pollock, S. (1998) Sexually Abused and Sexually Abusing Children in Substitute Care. Chichester: John Wiley

Farmer, E., Moyers, S., and Lipscombe, J. (2004) Fostering Adolescents. London: Jessica Kingsley 
Farmer E., Lipscombe J., and Moyers S. (2005) Foster carer strain and its impact on parenting and placement outcomes for adolescents. British Journal of Social Work, 35, 237-253

Farmer E., Selwyn J., Quinton D., Saunders H., Staines J., Turner W., and Meakings S. (2007) Children Placed with FCA: Experiences and progress 12 months on. Final Report to FCA, Hadley Centre for Adoption and Foster Care Studies. Bristol: University of Bristol, School for Policy Studies

Farrington, D. (1996) Understanding and Preventing Youth Crime. York: Joseph Rowntree Foundation

Gilligan, R. (2000) Adversity, resilience and young people: The protective value of positive school and spare time experiences. Children and Society, 14, 1, 37-47

Gilligan, R. (2001) Promoting Resilience: A resource guild on working with children in the care system. London, BAAF

Gilligan, R. (2007) Spare time activities for young people in care: what can they contribute to educational progress?, Adoption and Fostering, 31, 1 92-99

Harker, M., Dobel-Ober, D., Lawrence, J., Berridge, D., and Sinclair, R. (2003) Who takes care of education? Looked after children's perceptions of support for educational progress. Child \& Family Social Work, 8, 2, 89-100

Haydon, D. (2003). Teenage Pregnancy and Looked After Children / Care Leavers. Resource for Teenage Pregnancy Co-ordinators. Ilford: Barnardos

Hodges, J. and Tizard, B. (1989) Social and family relationships of ex-institutional adolescents. Journal of Child Psychology and Psychiatry, 30, 77-97

Jackson, S. (1994) Educating children in residential and foster care, Oxford Review of Education, 20, 3, 267-279

Jackson, S (2001) Nobody Ever Told us School Mattered: Raising the educational attainments of children in care. London: BAAF

Jackson, S. (2007) Progress at last? Guest Editorial to special issue, Education. Adoption and Fostering, 31, 1,3-5

Jackson S. and Ajayi S. (2007) Foster care and higher education. Adoption and Fostering, $31,1,62-72$

Jones, G. and Wallace, C. (1992) Youth, Family and Citizenship. Buckingham: Open University Press

Knight, A., Chase, E., and Aggleton, P. (2006) Teenage pregnancy among young people in and leaving care: Messages and implications for foster care, Adoption and Fostering Journal, 30, 1, 58-69

Lipscombe, J. (2006) Care or Control? Foster care for young people on remand. London: British Association for Adoption and Fostering

Lipscombe, J., Farmer, E., and Moyers, S. (2003) Parenting fostered adolescents: skills and strategies. Child and Family Social Work, 8, 4, 243-255

Lipscombe, J., Moyers, S., and Farmer, E. (2004) What changes in parenting' approaches occur over the course of adolescent foster care placements? Child and Family Social Work, 9, 347-357

Lowe, K., Hellett, L.J., and Stace, S. (2007) Teenagers in Foster Care: promoting positive 
relationships. A training course. Brighton: Trust for the Study of Adolescence

Marsh P. and Peel M. (1999) Leaving Care in Partnership: Family involvement with care leavers.. London: TSO

Moyers, S., Farmer, E., and Lipscombe, J. (2006) Contact with family members and its impact on adolescents and their foster placements,. British Journal of Social Work, 36, 541-559

Packman, J. and Hall, C. (1998) From Care to Accommodation. Support, protection and control in child care services. London: SO

Quinton D., Rushton A., Dance C.,, and Mayes D. (1998) Joining New Families: A study of adoption and fostering in middle childhood. Chichester: John Wiley

Roberts, R. (2006) Multidimensional Treatment Foster Care In England. Second Annual Report. London: Department for Education and Skills

Social Exclusion Unit (2003), A Better Education for Children in Care. London: Social Exclusion Unit / Office of the Deputy Prime Minister

Sinclair, I. (2005) Fostering Now: Messages from research. London: Jessica Kingsley

Sinclair, R., Garnett, L., and Berridge, D. (1995) Social Work and Assessment with Adolescents. London: National Children's Bureau

Sinclair, I., Gibbs, I., and Wilson K. (2004a) Foster Placements: Why they succeed and why they fail. London: Jessica Kingsley Publishers

Sinclair, I., Baker, C., Wilson, K., and Gibbs, I. (2004b) Foster Children: Where they go and how they get on. London: Jessica Kingsley

Stace, S. and Lowe, K. (2007) Reducing Risks for Young People in Foster Care: A UK study. Brighton: Trust for the Study of Adolescence

Taylor, C. (2006) Young People in Care and Criminal Behaviour. London: Jessica Kingsley

Thoburn, J., Norford, L., and Parvez Rashid, S. (2000) Permanent Family Placement for Children of Minority Ethnic Origin. London: Jessica Kingsley Publishers

Triseliotis, J., Borland, M., Hill, M., and Lambert, L.(1995) Teenagers and the Social Work Services. London: HMSO

Walker, M., Hill, M., and Triseliotis, J. (2002) Testing the Limits of Foster Care: Fostering as an alternative to secure accommodation. London: British Association for Adoption and Fostering

Ward, H. (Ed.) (1995) Looking After Children: Research into practice. The Second Report to the Department of Health on Assessing Outcomes in Child Care. London: HMSO 